\title{
Extractive Spectrophotometric Determination of Nortriptyline Hydrochloride Using Sudan II, IV and Black B
}

\author{
A. S. Amin and H. M. Saleh ${ }^{2}$ \\ 'Chemistry Department, Faculty of Science, Benha University, Benha, Egypt \\ 2Pharmaceutical Chemistry Department, Faculty of Pharmacy, Zagazig \\ University, Zagazig, Egypt.
}

\begin{abstract}
A simple spectrophotometric methods has been developed for the determination of nortriptyline hydrochloride in pure and in pharmaceutical formulations based on the formation of ion-pair complexes with sudun II $\left(\mathrm{S}_{\mathrm{II}}\right)$, sudan (IV) $\left(\mathrm{S}_{\mathrm{IV}}\right)$ and sudan black $\mathrm{B}\left(\mathrm{S}_{\mathrm{BB}}\right)$. The selectivity of the method was improved through extraction with chloroform. The optimum conditions for complete extracted colour development were assessed. The absorbance measurements were made at 534 . 596 and $649 \mathrm{~nm}$ for $S_{I I}, S_{I V}$ and $S_{B B}$ complexes, respective!y. The calibration graph was linear in the ranges $0.5-28.0,0.5-37.5$ and $0.5-31.0 \mu \mathrm{g} \mathrm{ml} \mathrm{l}^{-1}$ of the drug using the same reagents, respectively. The precision of the procedure was checked by calculating the relative standard deviation of ten replicate determinations on $15 \mu \mathrm{g}$ $\mathrm{ml}^{-1}$ of nortriptyline $\mathrm{HCl}$ and was found to be $1.7,1.3$ and $1.55 \%$ using $\mathrm{S}_{\mathrm{II}}, \mathrm{S}_{\mathrm{I}}$ : and $\mathrm{S}_{\mathrm{BB}}$ complexes, respectively. The molar absorptivity and Sandell sensitivity for each ion-pair were calculated. The proposed methods were successfully applied to the determination of pure nortriptyline $\mathrm{HCl}$ and in pharmaceutical formulations, and the results demonstrated that the method is equally accurate, precise and reproducible as the official method
\end{abstract}

Key words: Nortriptyline $\mathrm{HCl}$, Sudan II, IV and Black B, dosage forms

\section{Introduction}

Nortriptyline hydrochloride is $\mathrm{N}-3-(10,11$-dihydro-5H-dibenzo[a,d] cyclohept5-ylidene)propyl -N-methyl amine hydrochloride. It is used as antidepressant and trancuilizing agent. The drug and its formulations are official assayed in the British 
Pharmacopoeia ${ }^{(1)}$. The bulk drug is estimated by non-aqueous titration with perchloric acid using I-naphtholbenzein solution as indicator, whereas the ultra violet method was used for its formulations. Nortriptyline hydrochloride is commonly determined by high performance liquid chromatography ${ }^{(2)}$. Visible spectrophotometric method have also been developed for the determination of this drug using light green and orange $\mathrm{II}^{(3)}$. The other methods include capillary electrochromatography ${ }^{(4)}$ electrospray ionization mass spectrometry ${ }^{(5)}$, colorimetry $^{(2.6)}$ and electrometry ${ }^{(7-1+)}$ However, these methods are subjected to interferences from common additives and excipients. The purpose of this work was to develop a simple spectrophotometric method for the determination of nortriptyline in pure and in pharmaceutical formulations using sudan II, IV and black B as the coloured reagents. Solvent extraction was used to improve the selectivity of the method. The drug contents in pharmaceutical formulations were successfully determined by the proposed methods using the standard addition method.

\section{Experimental}

\section{Apparatus}

The spectra were recorded with a Perkin Elmer Lambada 3B recording double beam spectrophotometer, attached with $10.0 \mathrm{~mm}$ quartz cells was used for the absorbance measurements during the application of the proposed method under the optimum conditions. The $\mathrm{pH}$ measurements were made with an Orion research model $601 \mathrm{~A} /$ digital ionalyzer $\mathrm{pH}$ - meter

Reagents and Materials

De-ionized, freshly double distilled water was used throughout. All reagents were of analytical grade.

Stock solutions of $2 \times 10^{-3} \mathrm{M}$ of sudan II, IV and black B ( 1 /drich product) were prepared by dissolving the appropriate weight of the pure analytical reagent grade in least amount of acetone in a $100 \mathrm{ml}$ calibrated flask and complete to the mark with the same solvent.

Nortriptyline $\mathrm{HCl}$ stock standard solution, $250 \mathrm{\mu g} \mathrm{ml}^{-1}$, freshly prepared by dissolving $25 \mathrm{mg}$ of pure drug (ICN Chemicals) in water in a 100-ml calibrated flask 
and diluted to the mark with water. Working solutions were freshly prepared by appropriate dilution with water.

Acetate buffer solutions of $\mathrm{pH}$ values $1.63-5.66$ were prepared by mixing appropriate volume of $1.0 \mathrm{M}$ hydrochloric or acetic acids with $1.0 \mathrm{M}$ sodium acetate as recommended ${ }^{(15)}$.

General procectures

Aliquots of the drug solutions representing 5.00-375 $\mu \mathrm{g}$ of nortriptyline $\mathrm{HCl}$ were transferred into a series of separating funnels, $5.0 \mathrm{ml}$ of $\mathrm{pH} 2.34,3.76$ and 3.08 buffer solution for ion-pairs of $\mathrm{S}_{\mathrm{II}}, \mathrm{S}_{\mathrm{IV}}$ and $\mathrm{S}_{\mathrm{BB}}$, respectively and $3.0 \mathrm{ml}$ of $10^{-3} \mathrm{M}$ reagent solution were added to each separating funnel. The total volume of the aqueous phase was made upto $10 \mathrm{ml}$ with water. $10 \mathrm{ml}$ of chloroform were added and the contents were shaken for $3.0 \mathrm{~min}$ and allowed to stand for clear separation of the two layers. The chloroformic layer was passed through anhydrous sodium sulphate and the absorbance was measured at 534, 596 and $649 \mathrm{~nm}$ for $\mathrm{S}_{\mathrm{II}}, \mathrm{S}_{\mathrm{IV}}$ and $\mathrm{S}_{\mathrm{BB}}$, respectively, against a blank sample that had been treated equally.

\section{Analysis of pharmaceutical formulations}

Bulked samples were prepared by weighing 20 tablets and finding the average weight of one tablet. An amount of the bulked sample equivalent to $25 \mathrm{mg}$ of the active constituents was weighed accurately and transferred to a $100 \mathrm{ml}$ calibrated flask, shaken with $50 \mathrm{ml}$ of water. Then filtered if necessary and diluted to volume with water. An aliquot of this solution containing $100 \mu \mathrm{g}$ of the analyte was transferred to a separating funnel and analysed as shown in the General Procedure applying the standard addition technique.

\section{Results and Discussion}

\section{Optimistation of conditions for absorbance measurements}

The proposed methods are based on the formation of ion - pair complexes as a result of the reaction between nortriptyline $\mathrm{HCl}$ with $\mathrm{S}_{\mathrm{Il}}, \mathrm{S}_{\mathrm{IN}}$ or $\mathrm{S}_{\mathrm{BB}}$ reagents, which give red, pink or deep red coloured products, respectively. A solvent is needed to extract the ion-pair formed to increase the selectivity of the determination Preliminary experiments with a number of organic solvents commonly used $(1,2-$ 
dichloroethane, benzene, hexane, diethyl ether, chloroform, carbon tetrachloride) for solvent extraction showed that 1,2-dichloroethane and chloroform are useful solvents for all ion-pair complexes. The latter was selected because of its slightly higher sensitivity and considerably lower extraction ability for the reagents.

The effect of $\mathrm{pH}$ was examined by varying the $\mathrm{pH}$ values from 1.63 to 5.66 acetate buffer solutions and the results are shown in Fig ( 1 ). Maximum and constant absorbance values were obtained in the $\mathrm{pH}$ range $2.11-2.78,3.51-4.04$ and $2.78-3.38$ for $S_{11}, S_{I V}$ and $S_{B B}$ complexes, respectively. Outside these $\mathrm{pH}$ ranges, the absorbance decreased rapidly. Experimentally, it was found that more stable, more reproducible and faster development of the colour was achieved at $\mathrm{pH} 2.34,3.76$ and 3.08 for $S_{11} S_{I V}$ and $S_{B B}$ complexes, respectively.



Fig (1): Effect of $\mathrm{pH}$ on the absorbance of $20 \mu \mathrm{g} \mathrm{ml}$ nortriptylin complexed with $3 \times 10^{-4} \mathrm{M} \mathrm{S}_{\mathrm{II}} \mathrm{S}_{\mathrm{I}}$ and $\mathrm{S}_{\mathrm{BI}}$

Experiments were performed in which the volume of chloroform was kept constant at $10 \mathrm{ml}$, while that of the aqueous phase was varied between $2.5-25 \mathrm{ml}$. keeping the reagent content constant. The absorbance decreases on increasing the aqueous to chloroform phase - volume ratio. However, a ratio of $1: 1$ was chosen so as to compromise between maximum absorbance and a colourless blank; thus a linear relationship between absorbance and concentration could be achieved 
Fig. (2) shows the effect of reagent concentration used. At levels of about 3.0 $\mathrm{ml}$ of $10^{-3} \mathrm{M}$, the highest constant absorbance was obtained for the extracted ion-pair complexes. So this concentration was used for all further studies. Shaking times ranging from 0.5 to $5.0 \mathrm{~min}$ did not produce any change in the colour intensity and so $3.0 \mathrm{~min}$ shaking time was selected. Reproducible absorbance readings were obtained after a single extraction with $10 \mathrm{ml}$ of chloroform. Repeated extraction did not show an increase in the recovery percent results.

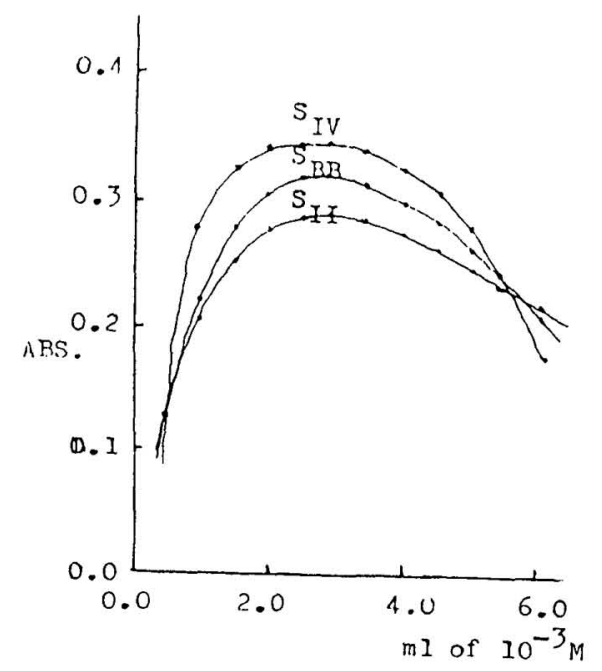

Fig (2): Effect of reagent concentration on $20 \mathrm{\mu g} \mathrm{ml}^{-1}$ nortriptylin complexed with $\mathrm{S}_{\mathrm{II}} \mathrm{S}_{\mathrm{I}} \cdot$ and $\mathrm{S}_{\mathrm{BB}}$.

Stoichiometry of the complexes

The molar ratio and Jab's continuous variation methods established the stoichiometry of the ion-pairs. The results obtained with these methods showed that the composition: of the ion-pair complexes were $(1: 1)$ (drug : reagent). The shape of the curves indicated that the complexes were labile. Hence a large excess of reagents must aiways be used to enhance the formation of the complex. The logarithmic stability constants of the ion-pair were calculated by applying the Harvey and Manning equation to the data obtained from the molar ratio and Jab's continuous variation methods. The results of $\mathrm{pK}$ values were $7.05,9.38$ and 8.06 using $S_{11}, S_{11}$ and $S_{13 \mid 3}$, respectively. 


\section{Absorption spectra}

The absorption spectra of the reaction products were recorded in the range of $400-750 \mathrm{~nm}$. Characteristic bands in the visible spectrum at $\lambda_{\max } 534,596$ and 649 $\mathrm{nm}$ for $\mathrm{S}_{\mathrm{II}}, \mathrm{S}_{\mathrm{IV}}$ and $\mathrm{S}_{\mathrm{BB}}$ - nortriptyline complexes were observed, whereas the absorbance of the drug or all reagent have a negligible absorbance at or near the $\lambda_{\max }$ regions. This absorption band was ascribed to the ion-pair complex formation.

\section{('alih:ation graphs}

Under the experimental conditions described above, linear calibration graphs were obtained over the range $0.5-28.0,0.5-37.5$ and $0.5-310 \mu \mathrm{g} / \mathrm{ml}$ of nortriptylıne $\mathrm{HCl}$ using $S_{11}, S_{I}$ and $S_{B B}$, respectively. For more accurate results, Ringbom optimum concentration ranges were calculated and recorded in Table (1). The molar absorptivity and Sandell sensitivity were also recorded in Table (1). Ten replicate determinations on a standard solution that contained $15 \mu \mathrm{g} \mathrm{ml} l^{-1}$ of nortriptyline $\mathrm{HCl}$ showed relative standard deviation of $1.7,1.3$ and $1.55 \%$ for $S_{I I}, S_{I V}$ and $S_{B B}$. respectively. The standard deviation of the absorbance measurements was 0.0026 , 0.0031 and 0.0029 obtained from a series of 13 blank solution. The limits of detection $\left(\mathrm{K}=3^{\prime}\right.$ and of determination $(\mathrm{K}=10)$ of the method were established according to the IUPAC definitions $\left(C_{1}=K S_{0} / s\right.$ where $C_{1}$ is the limits of detection, $S_{0}$ is the standard error of blank determination, $\mathrm{s}$ is the slope of the standard curve and $\mathrm{K}$ is the constant related to the confidence interval) ${ }^{(16)}$ and the values were recorded in Table (1). The correlation coefficient and the factors $a$ and $b$ of the regression line equation: $\mathrm{A}=\mathrm{a}+\mathrm{bC}$, for the reagents examined are summarized in Table (1). 
Table (1): Spectral, sensitivity and calibration graph characteristics of the analyte solutions. All the values are means of six determinations.

\begin{tabular}{|c|c|c|c|}
\hline Parameters & $\mathrm{S}_{\mathrm{II}}$ & $\mathrm{S}_{\mathrm{IV}}$ & $\mathrm{S}_{\mathrm{BB} 3}$ \\
\hline $\mathrm{pH}$ & 2.34 & 3.76 & 3.08 \\
\hline$\lambda_{\text {max }}$ & 534 & 596 & 649 \\
\hline Stoichiometry & $1: 2$ & $1: 2$ & $1: 2$ \\
\hline Beer's law limits $/ \mu \mathrm{g} \mathrm{m} \mathrm{m}^{-1}$ & $0.5-28.0$ & $0.5-37.5$ & $0.5-31.0$ \\
\hline Ringbom concentration range $/ \mu \mathrm{g} \mathrm{m} l^{-1}$ & $2.0-25.0$ & $2.0-34.0$ & $2.0-28.0$ \\
\hline Molar absorptivity $/ 1 \mathrm{~mol}^{-1} \mathrm{~cm}^{-1}$ & $4.18 \times 10^{3}$ & $5.20 \times 10^{3}$ & $4.64 \times 10^{3}$ \\
\hline Sandell sensitivity $/ \mu \mathrm{g} \mathrm{cm}^{-2}$ & 0.072 & 0.058 & 0.065 \\
\hline Detection limits / $\mathrm{ng} \mathrm{ml}^{-1}$ & 1.0 & 1.5 & 1.3 \\
\hline Quantification limits $/ \mathrm{ng} \mathrm{ml}^{-1}$ & 3.5 & 5.2 & 4.6 \\
\hline \multicolumn{4}{|l|}{ Regression equation } \\
\hline Slope (a) & 0.014 & 0.017 & 0.0155 \\
\hline Intercept (b) & -0.012 & -0.007 & +0.018 \\
\hline Correlation coefficient ( $\mathrm{r}$ ) & 0.9992 & 0.9998 & 0.9996 \\
\hline Standard deviation $(\%)$ & 0.79 & 0.58 & 0.67 \\
\hline Range of error $(\%)$ & $99.6 \pm 1.4$ & $100.2 \pm 1.2$ & $99.8 \pm 1.5$ \\
\hline $\mathrm{t}$ - value $(2.57)^{*}$ & 1.56 & 1.28 & 1.44 \\
\hline F-value $(5.05)^{*}$ & 2.31 & 2.09 & 2.25 \\
\hline
\end{tabular}

* Tabulated 1 - and F-value for five degree of freedom and $95 \%$ confidence level.

In order to determine the accuracy and precision of the recommended procedures, solutions containing five different concentrations of nortriplyline $\mathrm{HCl}$ were prepared and five absorbance measurements were made on each reaction product obtained according to the proposed method using $\mathrm{S}_{\mathrm{II}}, \mathrm{S}_{\mathrm{IV}}$ and $\mathrm{S}_{\mathrm{BB}}$. The results are given in Table 2. The over-all relative standard derivation of these 75 determinations was $1.42 \%$ and the mean standard analytical error (SD/n) was 0293 
Table (2): Accuracy and Precision of the proposed procedure

\begin{tabular}{|c|c|c|c|c|c|c|c|c|}
\hline & \multicolumn{3}{|c|}{$\mathrm{S}_{\mathrm{II}}$} & \multicolumn{3}{|c|}{$\mathrm{S}_{\mathrm{IV}}$} & \multicolumn{2}{|c|}{$\mathrm{S}_{\mathrm{BB}}$} \\
\hline No & Added & \multicolumn{2}{|c|}{$\begin{array}{c}\text { Found }^{*} \\
\pm \text { SD }\end{array}$} & Added & \multicolumn{2}{|c|}{$\begin{array}{c}\text { Found }^{*} \\
\pm \text { SD }\end{array}$} & Added & $\begin{array}{c}\text { Found* } \\
\pm \mathrm{SD}\end{array}$ \\
\hline$\overline{1-5}$ & 50 & \multicolumn{2}{|c|}{$4.46 \pm 0.61$} & 7.0 & \multicolumn{2}{|c|}{$7.04 \pm 0.39$} & 6.0 & $6.04 \pm 0.83$ \\
\hline $0-10$ & 10.0 & \multicolumn{2}{|c|}{$9.95 \pm 0.37$} & 14.0 & \multicolumn{2}{|c|}{$13.92 \pm 0.60$} & 12.0 & $12.11 \pm 0.92$ \\
\hline $11-15$ & 15.0 & \multicolumn{2}{|c|}{$15.13 \pm 0.53$} & 21.0 & \multicolumn{2}{|c|}{$21.12 \pm 0.48$} & 18.0 & $17.88 \pm 0.70$ \\
\hline $16-20$ & 20.0 & \multicolumn{2}{|c|}{$19.82 \pm 0.82$} & 28.0 & \multicolumn{2}{|c|}{$28.23 \pm 0.72$} & 24.0 & $24.25 \pm 0.87$ \\
\hline $21-25$ & 250 & \multicolumn{2}{|c|}{$25.27 \pm 0.77$} & 35 & \multicolumn{2}{|c|}{$34.70 \pm 0.57$} & 30.0 & $29.81 \pm 0.66$ \\
\hline \multirow[t]{2}{*}{ No } & & \multicolumn{3}{|c|}{ RS D \%** } & \multicolumn{3}{|c|}{ Standard analytical error*** } & \\
\hline & $S_{11}$ & $\mathrm{~S}_{\mathrm{IV}}$ & $\mathrm{S}_{\mathrm{BB}}$ & & $\mathrm{S}_{\mathrm{II}}$ & $S_{11}$ & $\mathrm{~S}_{\mathrm{BB}}$ & \\
\hline $1-5$ & 1.70 & 1.40 & 1.30 & & 0.27 & 0.17 & 0.37 & \\
\hline $6-10$ & 1.20 & 1.05 & 1.60 & & 0.17 & 0.27 & 0.41 & \\
\hline $11-15$ & 1.45 & 1.00 & 1.70 & & 0.24 & 0.21 & 0.31 & \\
\hline $16-20$ & 1.65 & 1.30 & 1.40 & & 0.37 & 032 & 0.39 & \\
\hline $21-25$ & 1.50 & 1.55 & 1.50 & & 0.34 & 0.25 & 0.30 & \\
\hline
\end{tabular}

*Average of five determinations

$* *$ Mean RSD $=1.42 \%$

*** Mean standard analytical error $=0.293$

\section{Interferences}

The interference 15 kinds of drugs and excipients on the determination of nortriptyline were examined. The drugs tested were added individually to a solution containing $15 \mu \mathrm{g} \mathrm{ml}^{-1}$ of notriptyline $\mathrm{HCl} \mathrm{A}$ maximum error of $\pm 3.0 \%$ in the absorbance reading was considered tolerable. The tolerance limits of galactose. glucose, lactose, sucrose, saccharin, citric acid, magnesium stearate, gum acacia, starch, sodium phosphate, $\mathrm{Vc}, \mathrm{V}_{\mathrm{A}}, \mathrm{VB}_{12}, \mathrm{~V}_{\mathrm{D}}$ and fluphenazine which usually present in nortriptyline formulations do not interfere up to 250 fold molar excess. The interference of the degradate products results from thermal and hydrolatic treatment with strong acid or base do not occurs up to 100 fold excess. So this drug can be 
determined in pure and in pharmaceutical formulations in routine analysis without interference from excipients, additives and degradation products.

\section{Anclysis of Pharmacentical formulations}

As can be seen from the results presented, most of the excipients, additives and degradation products normally present in pharmaceutical formulations do not interfere with the determination of nortriptyline. The proposed method was applied to the determination of this drug in its dosage forms applying the standard addition technique. The results are shown in Table 3 together with those obtained by the official method ${ }^{(1)}$ (depending on non- aqueous titration with $0.1 \mathrm{M}$ perchloric acid using 1-naptholbenzein solution as indicator). Moreover, in order to detect any losses of nortriptyline, the standard additions method was also used.

Table (3). Determination of nortriptyline $\mathrm{HCl}$ in different pharmaceutical formulations using $\mathrm{S}_{\mathrm{II}}, \mathrm{S}_{\mathrm{IV}}$ and $\mathrm{S}_{\mathrm{BB}}$ reagents

\begin{tabular}{|c|c|c|c|c|c|c|}
\hline \multirow{2}{*}{ Sample } & \multirow{2}{*}{$\begin{array}{l}\text { Taken } \\
\mu \mathrm{g} \mathrm{ml}^{-1}\end{array}$} & \multirow{2}{*}{$\begin{array}{l}\text { Added } \\
\qquad \mu \mathrm{gll}^{-1}\end{array}$} & \multicolumn{4}{|c|}{ Found $^{*} \mu \mathrm{g} \mathrm{ml}^{-1}$} \\
\hline & & & $\mathrm{S}_{\mathrm{II}}$ & $\mathrm{S}_{\mathrm{IV}}$ & $\mathrm{S}_{\mathrm{BB}}$ & Official method \\
\hline \multirow[t]{7}{*}{ Motival $^{a}$} & 5.0 & & 4.97 & 5.02 & 4.99 & +.92 \\
\hline & & 5.0 & 10.03 & 9.96 & 10.05 & 9.85 \\
\hline & & 10.0 & 15.10 & 14.92 & 14.95 & 15.15 \\
\hline & & 15.0 & 19.91 & 20.10 & 20.13 & 20.30 \\
\hline & & 20.0 & 24.88 & 25.18 & 24.80 & 24.70 \\
\hline & & 25.0 & - & 30.25 & 29.75 & 29.60 \\
\hline & & 30.0 & - & 35.50 & - & 35.50 \\
\hline
\end{tabular}

*Average of six determinations.

${ }^{a}$ Bristol- Myers Squibb Egypt Contain $10 \mathrm{mg}$ per tablet.

The performance of the recommended method was assessed by calculation of $\mathrm{t}$-and F-values. A mean values of Student's t- and F- values were obtained (Table 3), showing the absence of a systematic error in the method, as the corresponding tabulated $\mathrm{t}$ - and $\mathrm{F}$ - values for five degrees of freedom at $95 \%$ confidence level ${ }^{17}$ ) Therefore, it can be concluded that there is no significant difference between the proposed method and the official procedures. Table 3 gives the results of these applications 


\section{References}

1. British Pharmacopoeia, ed.1 (1993), Her Majesty's Stationery Office, London. P. 457.

2. Analytical Profiles of Drug Substances, Vol. 1, (1975), Academic Press, London, Florey K., 233-251.

3. Bhongade S.L., Kasture A.V., (1993), Indian J. Pharm. Sci., 55: 157.

4. Gillott N.C., Euerby M.R., Johnson C.M., Barrett D.A., Show P.N., (1998), Anct. ('ommun. 35: 217.

5. Selby D.S., Guilhous M., Murby J., Wells R.J., (1998), J. Mass spectr. 33: 1232.

6. Corona G.L., Facino R.M., (1968), Biochem. Pharm. 17: 2045.

7. Li X. F., Liu C.S., Roos P., Hansen E.B., Cerniglia C.E., Dovichi N.J., (1998), Electrophoresis 19: 3198.

8. Tserng K.Y., Mc Peak R.J., Dejak I., Tserng K., (!998), Ther. Drug Monit. 20 646.

9. Bordes A.-L., Schoellhorn B., Limoges B., Degrand C., (1999), Talanta 48: 201.

10. Hilberg T., Rogde S., Morland J., J(1999), Forensic. Sci. 44: 3.

11. Moriya F., Hashimoto Y., (1999), J. Forensic. Sci., 44: 10.

12. Greenway G.M, Dolman S.J. L., (1999), Analyst 124: 759.

13.Takayasu T., Holterman K., Ohshima T., Pounder D.L., (1998), J. Forensic. Sci. 43: 1213 .

14.Andres M.P.S., Sicilia D., Rubio S., Perez- Bendito D., (1998), J. Pharm. Sci, 87: 82.

15.Britton H.T.S., (1952), "Hydrogen Ions" $4^{\text {th }}$ ed. Chapman and Hall.

16.IUPAC Compendium of Analytical Nomenclature, (1981), Definitive Rules, ed. Irving H.M.N.H., Fresier H. West T.S., Pergamon Press, Oxford

17. Miller J.C., Miller J.N.,(1993), "statistics for Analytical Chemistry" $3^{\text {rd }}$ ed., Ellis Horwood, Chichester, (1993) 